\title{
Feline pemphigus foliaceus: original case series and a comprehensive literature review
}

Petra Bizikova ${ }^{1,2^{*}}$ and Amanda Burrows ${ }^{3}$

\begin{abstract}
Background: Since the first description of feline pemphigus foliaceus (PF) more than 30 years ago, numerous case reports have been published, while larger case series have remained rare. This large body of information, if extrapolated, could address clinical discrepancies and expand our knowledge about the treatment of feline PF.

This manuscript reviews cases of feline PF published between 1950 and 2016 and adds additional 35 original cases to provide further insight into the clinical aspect and treatment outcome of this disease.

Results: Feline PF, while being a primary acantholytic pustular dermatosis, presents most often with crusts and erosions that predominantly affect the face and feet. More than half of cats with active disease exhibits non-dermatological signs such as lethargy, fever and/or anorexia. The prognosis of feline PF is good as the majority of cats rapidly achieve disease control even with the most basic treatment such as glucocorticoid monotherapy. Most PF-affected cats, however, require long-term treatment and, like other autoimmune diseases, feline PF has a tendency to relapse spontaneously or with treatment changes.

Conclusions: Therefore, despite the overall good prognosis cats with PF can be given, owners should be informed and prepared for these circumstances, which may reduce the risk of euthanasia in the case of disease relapse, and improve treatment compliance.
\end{abstract}

Keywords: Auto-immune skin diseases, Auto-immunity, Feline, Cat, Dermatology, Pemphigus, Skin

\section{Background}

Pemphigus foliaceus (PF) is the most common autoimmune skin disease recognized in cats $[1,2]$. It is defined as a pustular erosive and crusting dermatosis commonly involving the face, ears and feet [3]. In addition, variable frequencies of involvement of the periareolar (2-20\%) and claw folds (30-90\%), as well as generalized distribution have been reported [1, 4-8].

The diagnostic approach to feline PF has not changed in over 30 years in veterinary medicine, and it is still based on clinical and microscopic confirmation of a subcorneal pustular dermatitis (i.e. presence of pustules, secondary superficial erosions and crusts) with

\footnotetext{
*Correspondence: pbiziko@ncsu.edu

1 Department of Clinical Sciences, College of Veterinary Medicine, North Carolina State University, 1060 William Moore Drive, Raleigh, NC 27607, USA ${ }^{2}$ Center for Comparative Medicine and Translational Research, North Carolina State University, Raleigh, NC, USA

Full list of author information is available at the end of the article
}

acantholysis. Indeed, the list of diseases presenting with primary subcorneal pustules with acantholysis in cats is limited to PF, and to anecdotal reports of pustular dermatophytosis; the latter has been reported to exhibit minimal to no acantholysis [9]. Bullous impetigo, a subcorneal pustular dermatitis with variable degree of acantholysis caused by Staphylococcus aureus and pseudintermedius in people and dogs, has not been well characterised in cats [10-12]. Immunological testing for antikeratinocyte autoantibodies by direct or indirect immunofluorescence is neither commercially available for cats, nor is the sensitivity and, particularly, specificity of such tests known for feline PF.

Various treatment modalities have been published over the years for feline PF. Glucocorticoids are the most frequently selected drugs despite reports of their variable efficacy ranging from 35 to $97 \%$ [8, 13-15]. Chlorambucil, aurothioglucose (gold salts), ciclosporin and even azathioprine have been used when glucocorticoids failed 
to provide adequate control, or when cats were unable to tolerate prolonged glucocorticoid therapy due to concurrent health issues $[4,6,7,13,14]$. Due to the current unavailability of the original formulation of aurothioglucose and the sensitivity of cats to azathioprine [16, 17], chlorambucil and ciclosporin remain the most commonly recommended adjunctive drugs for the management of feline PF $[3,15]$. Nonetheless, the evidence of efficacy for these drugs to induce disease control and to maintain it is limited $[6,7]$.

There are only few large case series of feline PF published [1, 6-8], but many individual case reports can be found. This large body of information, if extrapolated, could address discrepancies in clinical presentation and expand our knowledge about the treatment of cats with PF. As such, the goal of this study was to perform a comprehensive review of all cases of feline PF published between 1950 and 2016 with a focus on clinical aspects and treatment outcomes. A retrospective analysis of additional 35 cats with PF from both authors' institutions was performed and expanded the data available for analysis.

\section{Methods}

\section{Original case series}

Cats included in this report were selected from cases diagnosed and treated at the authors' institutions between January 2000 and June 2017 using following criteria: i) clinical evidence of superficial pustules and/or secondary erosions and/or crusts; ii) lack of response to appropriate antibiotic treatment (of at least 3-week duration); iii) presence of numerous acantholytic cells on cytology and/or histopathology, and iv) a follow-up of at least 3 months. There was no age restriction. Information about the signalment, lesion distribution, presence of systemic signs, treatment outcome and the time of follow-up was extracted and recorded in a tabular form. If disease control (DC) was achieved, the time to DC and the drug(s) given at the time of $\mathrm{DC}$ were recorded. Disease control was defined as a time at which new lesions ceased to form and established lesions (pustules, erosions and crusts overlying active erosions) had mostly or fully healed. When compared to the human PF outcome measures, the DC definition used here would more correspond with "the end of consolidation phase" timing in human PF [18]. Finally, information about the treatment discontinuation and relapse episodes was noted.

\section{Comprehensive literature review}

A literature search for any study detailing clinical and/or treatment evaluation of feline PF cases published between 1950 and 2016 was conducted using four databases: Pubmed (pubmed.gov), Web of Science (Thomson Reuters), CAB Abstracts (EBSCOhost Research Databases) and $\mathrm{CAB}$ Abstracts Archive (EBSCOhost Research Databases). Reviews that did not include clinical cases were excluded. The following search strategy was used for all databases:

- (pemphigus OR autoimmune skin OR auto-immune skin) AND (cat OR cats OR feline OR felines) NOT (human OR humans OR child" OR patient")

There was no date or language restriction placed on the manuscript search. Additionally, the bibliographies of all selected articles and published abstracts from annual meetings of the European Society of Veterinary Dermatology/European College of Veterinary Dermatology, American Academy of Veterinary Dermatology/ American College of Veterinary Dermatology and World Congresses of Veterinary Dermatology between 1995 and 2016 were screened for additional reports.

Only publications in which the author(s) described superficial pustular and/or erosive and/or crusting dermatitis with microscopic confirmation of acantholysis were included. Review articles and publications not containing primary PF cases or containing cases already published elsewhere, or publications with cases of unclear etiology (not fulfilling the clinical and microscopic criteria listed above) were excluded (Fig. 1). There was no age restriction set for the included cats. No specific length of follow-up was required.

Data regarding the signalment, clinical features (lesion distribution, presence of systemic signs) and treatment outcome (achievement of DC, time to DC, drugs at the time of DC) were extracted and presented in a tabular form by PB. Missing data for incompletely described (or photographically documented) cases were marked as "not reported" and accounted for in the percentage calculations. The lesion symmetry was recorded using both the authors' description and images from the publications. The data were verified by the second author (MB) and any discrepancies were resolved by consensus.

\section{Statistical analyses}

The comparison of independent categorical parameters of continuous values was made using Mann-Whitney $\mathrm{U}$ test. The threshold of significance was set at $P=0.05$. Statistic analyses were made using Prism 7 (Graphpad software, San Diego, CA, USA).

\section{Results}

Signalment and clinical features

\section{Original case series}

Thirty-five cats met the inclusion criteria. Acantholysis was confirmed in all cases by cytological evaluation, and in most cases by histological evaluation (24/35; 69\%). Most cats were middle aged at the onset of their disease (median 


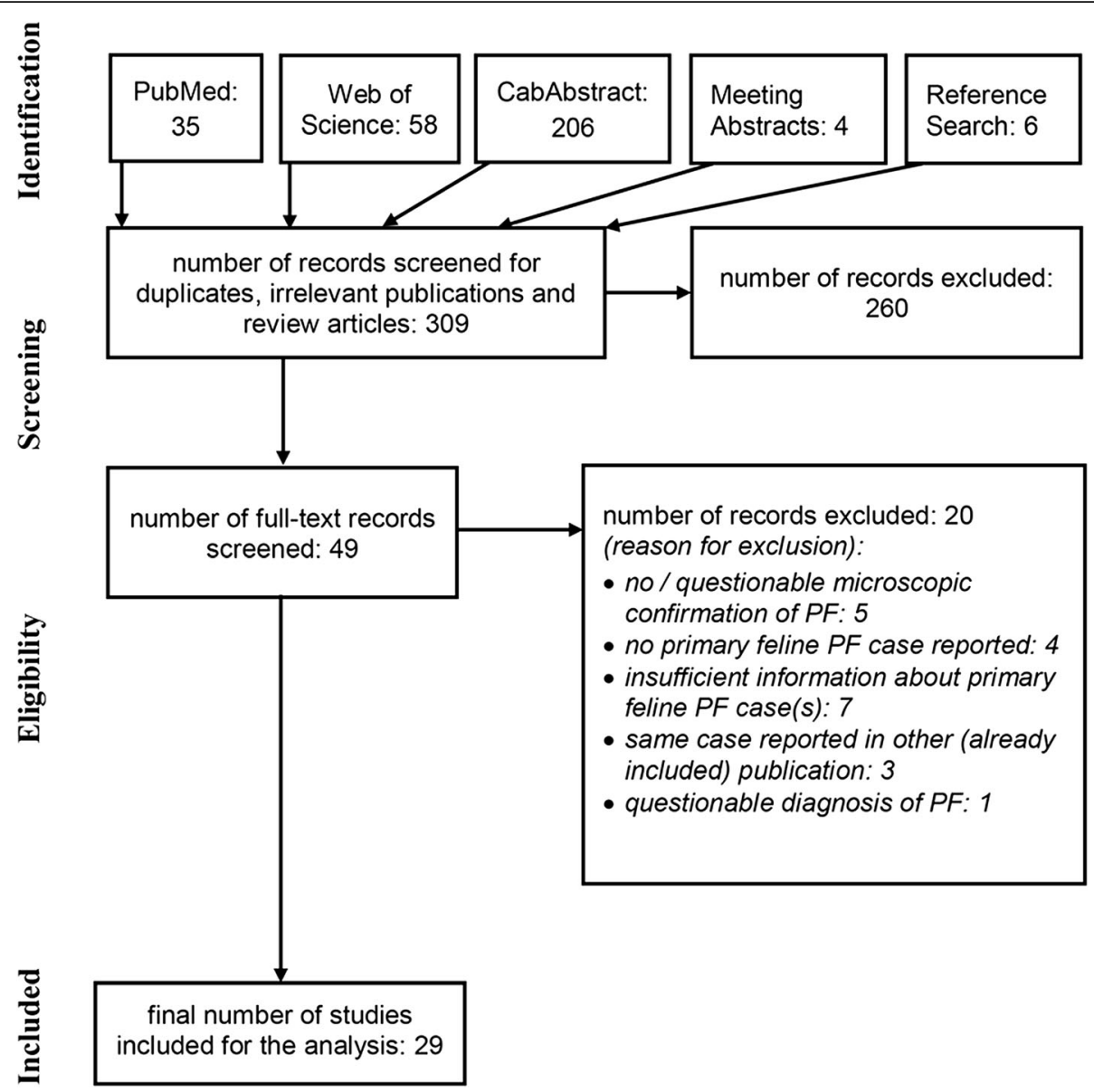

Fig. 1 A flow chart diagram depicting the performed literature search. Only publications in which the author(s) described superficial pustular and/or erosive and/or crusting dermatitis with microscopic confirmation of acantholysis were included. Review articles and publications not containing primary PF cases or containing cases already published elsewhere, or publications with cases of unclear etiology (not fulfilling the clinical and microscopic criteria listed above) were excluded. Excluded publications are referenced [74-93]

(mean): 6 (6.8) years; range: $0.4-15$ years), and female cats were marginally over-represented (female-to-male ratio of 1.7). Cats affected with PF belonged to variety of different breeds including Domestic short-haired cats (19/35; 54\%), Siamese cats $(3 / 35 ; 9 \%)$, Domestic medium-haired cats $(2 /$ $35 ; 6 \%)$, Ragdoll cats $(2 / 35 ; 6 \%)$, and one of each of the following breeds (Birman, British short-haired, Burmese, Cornish rex, Himalayan, Napoleon, Russian blue, Tonkinese and Turkish Van cats). A specific trigger was not confirmed for any cat, although a regular vaccination closely preceded the onset of the PF in two cats (6\%). In one of these cats, a long-term complete remission off drugs without relapses was reported (follow up: 55 months).

Skin lesions in PF-affected cats consisted of pustules, erosions and/or crusts as expected based on the inclusion criteria. They were symmetric in the majority of cats $(33 / 34$; $97 \%)$ for which this information was available, and usually affected two or more body regions (28/ 35 ; 80\%). The most commonly affected body regions were the face/head $(31 / 35 ; 89 \%)$ and limbs $(27 / 35 ; 77 \%)$; the most commonly affected skin sites were the pinnae (32/35; 91\%) and claw folds (26/35; 74\%) (Figs. 2 and 3). Pruritus status was reported in 32 cats, 10 of which were pruritic. The degree of pruritus was noted in seven of the ten cats (mild: 3, moderate: 2, severe: 2). Systemic signs were recorded in 22 of 35 cats (63\%); 21 of 35 cats (60\%) were lethargic, and 10 of 35 cats (29\%) were febrile.

\section{Comprehensive literature review}

The literature search is summarized in Fig. 1. Twenty-nine studies reporting cats with PF were selected $[1,4-8,13,19-40]$. Twenty-one publications reported a single case, two reported two to five cases, three reported 6 to 10 cases and three reported 11 to 57 cases. Twenty-six publications were journal articles (14 in English, six in French, two in Japanese, two in Portuguese and one in Danish languages), three were abstracts (in English) and one was a thesis (in Portuguese). 


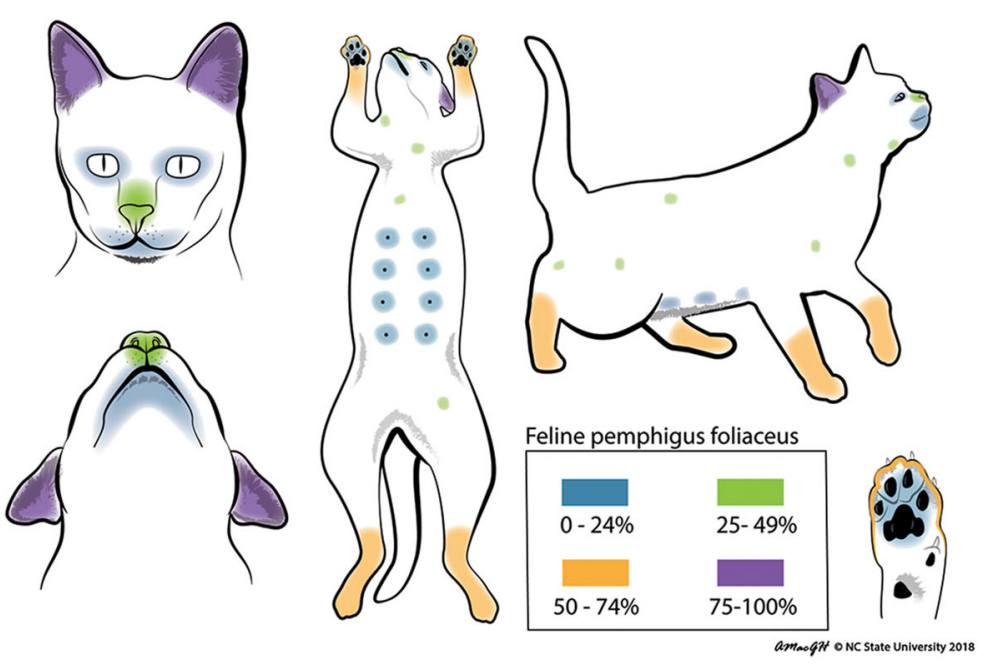

\begin{tabular}{|c|c|c|c|}
\hline & Original Cases & Literature Review & Total \\
\hline $\begin{array}{l}\text { Lesions localized to } 1 \text { body } \\
\text { area (localized) } \\
\text { Lesions localized to }>1 \text { body } \\
\text { area (generalized) }\end{array}$ & $\begin{array}{l}7 / 35(20 \%) \\
28 / 35(80 \%)\end{array}$ & $\begin{array}{l}29 / 151(19 \%) \\
122 / 151(81 \%)\end{array}$ & $\begin{array}{l}36 / 186(19 \%) \\
150 / 186(81 \%)\end{array}$ \\
\hline Head/Face & $31 / 35(89 \%)$ & $122 / 145(84 \%)$ & $153 / 180(85 \%)$ \\
\hline Pinnae & $32 / 35(91 \%)$ & $112 / 144(78 \%)$ & $144 / 179(80 \%)$ \\
\hline Nose & $18 / 35(51 \%)$ & $46 / 136(34 \%)$ & $64 / 171$ (37\%) \\
\hline Eyelids/Periocular & $11 / 35(31 \%)$ & $21 / 128(16 \%)$ & $32 / 163(20 \%)$ \\
\hline Limbs/Feet & $27 / 35(77 \%)$ & $103 / 144(72 \%)$ & $130 / 179(73 \%)$ \\
\hline Footpads & $9 / 35(26 \%)$ & $16 / 77(21 \%)$ & $25 / 112$ (22\%) \\
\hline Claw folds & $26 / 35(74 \%)$ & $74 / 142(52 \%)$ & 100/177 (56\%) \\
\hline claw folds only & $3 / 35(9 \%)$ & $11 / 87(13 \%)$ & $14 / 122(11 \%)$ \\
\hline Neck/Trunk & $19 / 35(54 \%)$ & $58 / 137(42 \%)$ & $77 / 172(45 \%)$ \\
\hline Areola/Periareolar & $7 / 35(20 \%)$ & $10 / 137(7 \%)$ & $17 / 172(10 \%)$ \\
\hline Perianal/Perigenital & $4 / 35(11 \%)$ & $5 / 145(3 \%)$ & $9 / 180(4 \%)$ \\
\hline Pruritus & $10 / 32(31 \%)$ & $83 / 114(73 \%)$ & 93/146 (64\%) \\
\hline Systemic signs (general) & $22 / 35(63 \%)$ & $13 / 30(43 \%)$ & $35 / 65(54 \%)$ \\
\hline fever & $10 / 35(29 \%)$ & $18 / 67(27 \%)$ & $28 / 102(27 \%)$ \\
\hline lethargy & $21 / 35(60 \%)$ & $33 / 72(46 \%)$ & $54 / 107(50 \%)$ \\
\hline
\end{tabular}

Fig. 2 Feline pemphigus foliaceus lesion distribution diagram and individual data of lesion distribution (based on the original cases and the literature review)

A total of 162 cats with PF were included for review. Acantholysis was confirmed histologically in 146 of 162 cats $(90 \%)$ and/or by cytological evaluation in 31 of 162 cats (19\%). The exact age of onset of the disease was reported for 72 cats, with most cats being middle aged (median (mean): 7 (7.2) years; range: $0.25-16$ years). In the remaining studies, age was reported as median and/ or mean. In these studies, the median age of onset was 5 years (57 cats) [6] and 5.5 years (10 cats) [1], and the mean was 5.4 years (10 cats) [1], 6 years ( 8 cats) [4] and 7 years (15 cats) [7]. Females marginally out-numbered males (female-to-male ratio of 1.3). Cats affected with PF belonged to a variety of different breeds including Domestic short-haired (97/162; 60\%), Siamese (13/162; 


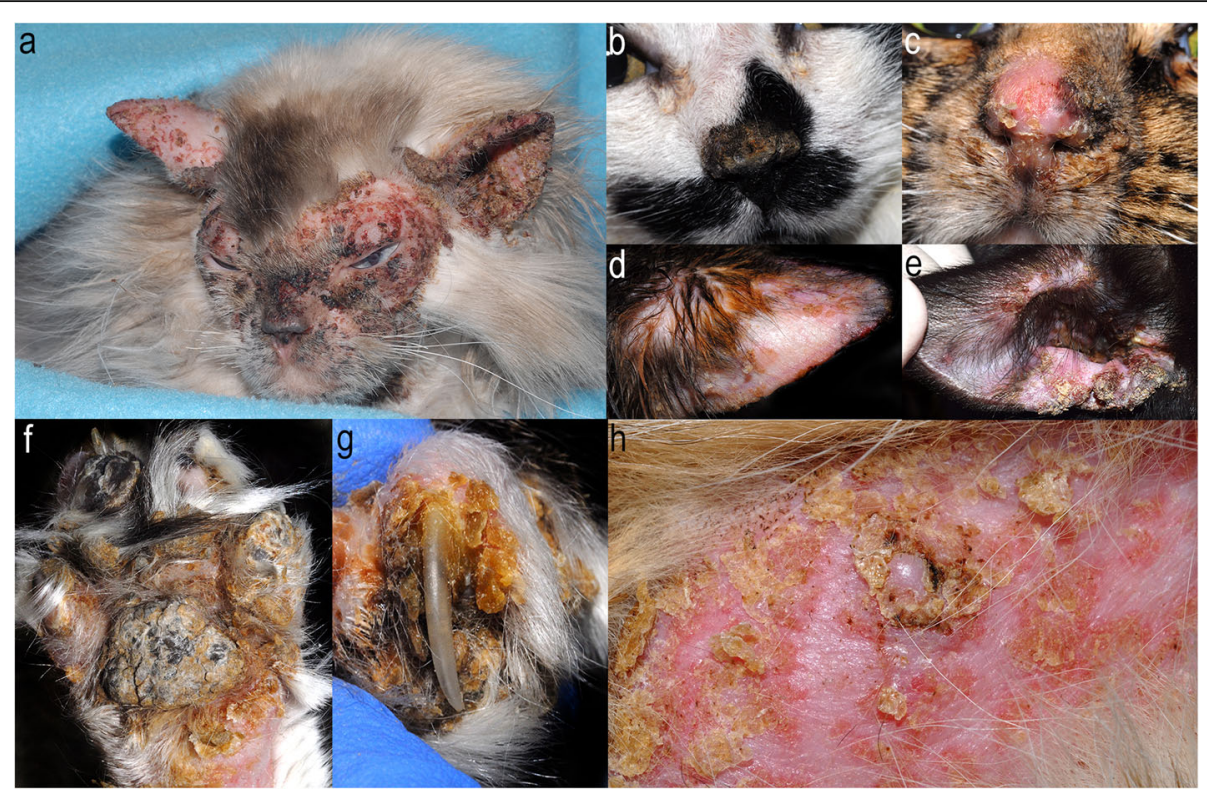

Fig. 3 Clinical photos depicting characteristic skin lesions and their distribution. a multifocal pinpoint to coalescing erosions and crusts on the face and pinnae; $\mathbf{b}$, $\mathbf{c}$ nasal planum erosions and crusts; $\mathbf{d}$, e erosion and crusts on convex and concave pinnae; $\mathbf{f}$ thick crusting and hyperkeratosis on a pawpad; $\mathbf{g}$ thick crusting and purulent exudation affecting the nail fold; $\mathbf{h}$ multifocal erosions and crusts near the areolar region. Acknowledgements for clinical photographs: Michael Rossi (a), Aurore Laprais (b), Marcy Murphy (d)

$8 \%)$, Persian and Persian-crossbred (10/162; 6\%), Burmese $(7 / 162 ; 4 \%)$, Himalayan $(5 / 162 ; 3 \%)$, Domestic medium-haired $(5 / 162 ; 3 \%)$ and Domestic long-haired (5/162; 3\%), Maine Coon (4/162; 3\%), Birman (3/162; $2 \%)$, Russian blue $(3 / 162 ; 2 \%)$, Tonkinese $(2 / 162 ; 1 \%)$, and Bobtain cats $(2 / 162 ; 1 \%)$ and one of each of the following breeds (American blue, Chinchilla, Cornish rex, Ragamuffin, Scottish fold and Somali cats).

In eight cats, a possible drug-association was proposed $[6,20,22,23,27,40]$. In three of these eight cats, PF resolved spontaneously after the suspected drug(s) (cimetidine (1 cat), econazole/neomycin/triamcinolone/amoxicillin (1 cat), itraconazole/lime sulfur (1 cat)) were withdrawn; one cat experienced a flare up of disease when the offending drug (cimetidine) was restarted [6, 20, 23]. Another cat, in which doxycycline was suspected as the trigger, experienced a disease flare up after accidental reintroduction of the antibiotic. Disease control in this cat was achieved with an immunosuppressive treatment, which was eventually discontinued without further relapse [22]. One cat (methimazole suspected) had no available follow up, and the remaining three cats (cefovecin (1 cat), clindamycin/carprofen $(1$ cat $)$ and ipodate ( 1 cat $)$ ) were successfully controlled with immunosuppressants, which were eventually withdrawn in two cats (cefovecin and clindamycin/carprofen) without reported relapse [6, 27, 40]. Re-exposure with the suspected drug(s) did not occur in the four latter cats.

Concurrent disease-association was proposed in three cats (thymoma (2) and leishmaniosis (1)) [28, 32, 35].
Thymoma removal and short-term immunosuppressive treatment resulted in a rapid DC in one cat [35]. In the other cat, DC was achieved with immunosuppressive treatment, but neither information about thymoma management nor complete drug withdrawal was available [32]. The cat with leishmaniosis received treatment for both leishmaniosis and PF; after reaching DC, the latter was later discontinued without further relapse [28].

Finally, one cat received standard vaccination shortly before the PF onset [38]. In this cat, a DC was achieved with immunosuppressive treatment, which was later completely stopped without a subsequent disease relapse.

Skin lesions in PF-affected cats consisted of pustules, erosions and crusts as expected based on the inclusion criteria. Due to the 34-year span of the selected publications and the inconsistency in the data reporting, not all information was available for each cat. The lesion distribution was symmetric in the majority of cats (127/131; 97\%), and lesions usually affected two or more body regions (122/151; 81\%). The two most commonly affected body regions were the face/head (122/145; 84\%) and limbs (103/144; 72\%); the most commonly affected skin sites being the pinnae (112/ 144; 78\%) and claw folds (74/142; 52\%) (Fig. 2). The majority of cats $(83 / 114 ; 73 \%)$ were pruritic, and the degree of pruritus was noted in 13 of these 83 cats (mild: 8, moderate: 4, severe: 1). Non-dermatological signs such as the presence of systemic signs (in general) or specific comments regarding lethargy and fever were reported in 13/30 (43\%), 33/72 (46\%) and 18/67 (27\%) cats, respectively. 


\section{Treatment and outcome \\ Original case series}

Treatment and outcome information was available for all 35 cats. The median time of follow-up was 15 months (mean: 23 months; range: 3.5-55 months). Disease control was achieved in 31 cats (89\%) (Fig. 4). The median time to achieve DC was 22 days (mean: 37 days; range: 7-269 days).

Spontaneous remission was not observed in any cat. In approximately half of the cats, DC was achieved using glucocorticoid monotherapy $(16 / 31 ; 52 \%)$ with standard dosages accepted in veterinary medicine [41]. Prednisolone was utilised most frequently $(13 / 31 ; 42 \%)$, while prednisone, triamcinolone acetonide and dexamethasone were used in one cat each. The times to DC, median and mean dosages at the time of DC, where indicated, and the cumulative dosages of glucocorticoids received by the cats prior to DC (calculated as prednisolone equivalent per $5 \mathrm{~kg}$ cat $[41,42])$ are listed in Table 1 . The highest initial dosages of these drugs were identical to those used at the time of $\mathrm{DC}$ with the exception of triamcinolone acetonide (1 cat; initial dosage: $0.6 \mathrm{mg} / \mathrm{kg} /$ day).

Twelve of the 31 cats $(39 \%)$ received high-dose oral glucocorticoid pulse therapy using principles similar to

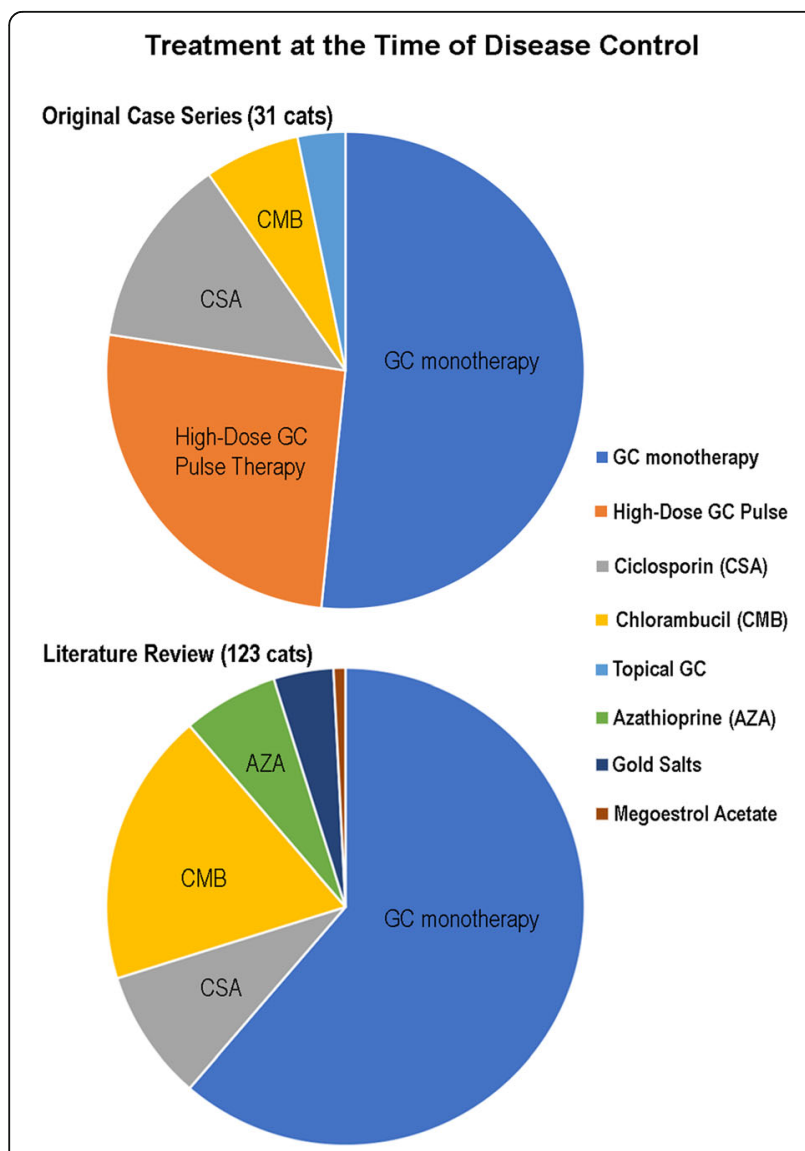

Fig. 4 Pie charts of treatment regimens at the time of disease control those described in dogs $(\sim 10 \mathrm{mg} / \mathrm{kg}$ of prednisolone or prednisolone equivalent daily for three consecutive days, followed by a reduced dosage of a selected glucocorticoid (target: $<2 \mathrm{mg} / \mathrm{kg} /$ day of prednisolone or of its equivalent). Glucocorticoid pulse therapy could be repeated, at discretion of the clinician, if active lesions continued to appear after the dosage was tapered, but no more than one pulse per week was permitted [43]. For the pulse therapy, dexamethasone (9 cats; median: 1 $\mathrm{mg} / \mathrm{kg}$ daily for 3 days [range: $0.8-1.2 \mathrm{mg} / \mathrm{kg}$ ]), methylprednisolone (1 cat; $10 \mathrm{mg} / \mathrm{kg}$ ), prednisolone (1 cat; 10 $\mathrm{mg} / \mathrm{kg}$ ) or triamcinolone acetonide (1 cat; $1 \mathrm{mg} / \mathrm{kg}$ ) was utilised. Eight of the 12 cats (67\%) reached DC with pulse therapy only; seven of them (58\%) within 1 month. One ( 7 cats) to two (1 cat) pulse therapies were needed to induce DC in these cats (Table 2). In comparison, 14 of the 16 cats $(88 \%)$ that received standard glucocorticoid monotherapy achieved DC within 1 month. The time to DC and the cumulative dosages of glucocorticoids received by cats prior to DC (calculated as prednisolone equivalent per $5 \mathrm{~kg}$ cat) are listed in Table 2 . There was no statistically significant difference in the time to DC and the cumulative dose of glucocorticoids between the pulse and standard glucocorticoid monotherapy $(P=$ 0.53 and $P=0.33$, respectively; Mann-Whitney $U$ test) (Fig. 5).

Six of the 31 cats (19\%) received non-steroidal immunosuppressive drugs such as ciclosporin or chlorambucil in combination with oral and/or topical glucocorticoids (Table 1). The times to DC, median and mean dosages of ciclosporin and chlorambucil at the time of DC, and the cumulative dosages of glucocorticoids (where indicated) received by the cats prior to DC (calculated as prednisolone equivalent per $5 \mathrm{~kg}$ cat) are listed in Table 1. The initial (highest) dosages of ciclosporin and chlorambucil were identical to those reported at the time of DC. Five cats received concurrent oral glucocorticoids at the time of DC including prednisolone ( 2 cats; median/mean dosage: $1 \mathrm{mg} / \mathrm{kg} /$ day [range: $0.5-$ $1.5 \mathrm{mg} / \mathrm{kg} /$ day]), triamcinolone acetonide (2 cats; $0.2 \mathrm{mg} /$ $\mathrm{kg} /$ day [range: $0.1-0.3 \mathrm{mg} / \mathrm{kg} /$ day]) or dexamethasone (1 cat; $0.1 \mathrm{mg} / \mathrm{kg} /$ day).

Topical glucocorticoids (most often $0.1 \%$ mometasone cream) were utilised at the time of DC in four cats. In one cat $(3 \%)$, this was the sole treatment that led to DC within 28 days.

Five of the 30 cats in which DC was achieved with systemic treatment (17\%) discontinued all systemic drugs without a disease flare up during the subsequent follow-up time period (range: 7 to 55 months). One cat required topical glucocorticoids to maintain DC. One cat was maintained with topical betamethasone ointment, but experienced a flare up of disease after 6 months of treatment at which point the owner elected euthanasia. 
Table 1 Original case series: Treatment details at the time of disease control

\begin{tabular}{|c|c|c|c|c|c|c|c|c|c|c|c|}
\hline \multirow[t]{2}{*}{$\begin{array}{l}\text { Treatment at the Time of } \\
\text { Disease Control }\end{array}$} & \multirow[t]{2}{*}{ \# cats } & \multirow[t]{2}{*}{$\%$ cats } & \multicolumn{3}{|c|}{ Time to Disease Control (days) } & \multicolumn{3}{|c|}{$\begin{array}{l}\text { Dosages of GC at the Time of } \\
\text { Disease Control (mg/kg/day) }\end{array}$} & \multicolumn{3}{|c|}{$\begin{array}{l}\text { Cumulative Dose of GC up } \\
\text { to } D C(\mathrm{mg}) \text { (prednisolone } \\
\text { equivalent for } 5 \mathrm{~kg} \text { cat) }\end{array}$} \\
\hline & & & Median & Mean & Range & Median & Mean & Range & Median & Mean & Range \\
\hline Standard GC Monotherapy & 16 & $52 \%$ & 14 & 21 & $(7-50)$ & & & & 280 & 306 & $(35-640)$ \\
\hline prednisolone & 13 & $42 \%$ & 14 & 18 & $(8-31)$ & 3 & 3 & $0.7-5.5$ & 280 & 298 & $(35-600)$ \\
\hline prednisone & 1 & $3 \%$ & 12 & & & 4.4 & & & NA & & \\
\hline triamcinolone & 1 & $3 \%$ & 42 & & & 0.3 & & & 640 & & \\
\hline dexamethasone & 1 & $3 \%$ & 50 & & & 0.1 & & & 72 & & \\
\hline $\begin{array}{l}\text { Non-Steroidal } \\
\text { Immunosuppressants as a } \\
\text { Monotherapy or Combination } \\
\text { Therapy }\end{array}$ & 6 & $19 \%$ & 58 & 105 & $(24-269)$ & & & & 433 & 412 & $(180-710)$ \\
\hline GC+ ciclosporin & 2 & $6 \%$ & 149 & 149 & $(28-269)$ & 6 & 7 & $(5-10)$ & 490 & 490 & $(270-710)$ \\
\hline$G C+$ ciclosporin + topical GC & 2 & $6 \%$ & 52 & 52 & $(24-80)$ & & & & 449 & 449 & $(433-465)$ \\
\hline GC + chlorambucil & 1 & $3 \%$ & 36 & & & 0.2 [every & 0.2 [every & (0.15-0.3) [every & 180 & & \\
\hline chlorambucil + topical GC & 1 & $3 \%$ & 192 & & & & & & & & \\
\hline Topical GC only & 1 & $3 \%$ & 28 & & & & & & & & \\
\hline
\end{tabular}

Cumulative dose of glucocorticoids up to the time of disease control was calculated as a prednisolone equivalent for $5 \mathrm{~kg}$ cat. Following estimated steroid equivalency conversions were used: dexamethasone and triamcinolone acetonide about seven times and methylprednisolone 1.3 times more potent than prednisolone [41, 42]. Due to the low bioavailability of prednisone in cats [94-96], the equivalency conversion between prednisone and prednisolone could not be determined and, therefore, the single case in which prednisone was used to induce disease control was excluded from the cumulative dose calculation

The remaining 24 cats $(80 \%)$ were maintained on variety of systemic drugs with or without topical glucocorticoids (Table 3). Twelve of the 24 cats (50\%) were maintained on reduced dosages of glucocorticoids, and 12 cats (50\%) received non-steroidal immunosuppressants such as ciclosporin (7 cats) or chlorambucil ( 5 cats) as a monotherapy ( 5 cats), or in combination with glucocorticoids (7 cats). Topical glucocorticoids (mometasone or triamcinolone) were used concurrently with systemic treatment in four cats.

Disease flare ups were reported in the majority of cats (24/31; 77\%). In 22 cats, disease flare ups coincided with a reduction of the drug dosage or treatment discontinuation. Two cats experienced intermittent flare ups of PF with the maintenance treatment.

Adverse effects related to treatment were reported in nine cats and included transient diabetes mellitus (3/9; $33 \%)$, mild to severe, undefined, upper respiratory tract disease $(3 / 9 ; 33 \%)$, hepatopathy $(3 / 9 ; 33 \%)$, polyuria/ polydipsia $(2 / 9 ; 22 \%)$, urinary tract infection $(1 / 9 ; 11 \%)$ and bullous keratopathy $(1 / 9 ; 11 \%)$. Two of the nine cats with adverse effects received one or two high-dose glucocorticoid pulse treatments (mild upper respiratory

Table 2 Original case series: Details of the high-dose pulse glucocorticoid therapy

\begin{tabular}{|c|c|c|c|c|c|c|c|c|c|c|c|}
\hline \multirow[t]{2}{*}{ High-Dose Glucocorticoid Pulse Therapy } & \multirow[t]{2}{*}{ \# cats } & \multirow[t]{2}{*}{$\%$ cats } & \multicolumn{3}{|c|}{ Time to Disease Control } & \multicolumn{3}{|c|}{ Cumulative Dose of Steroids } & \multicolumn{3}{|c|}{ Number of Pulses } \\
\hline & & & Median & Mean & Range & Median & Mean & Range & Median & Mean & Range \\
\hline $\begin{array}{l}\text { Total \# of cats receiving high dose GC } \\
\text { pulse therapy }\end{array}$ & 12 & & & & & & & & 1 & 2 & $(1-3)$ \\
\hline $\begin{array}{l}\text { Cats achieving DC within } 4 \text { weeks of the } \\
\text { high dose GC pulse therapy }\end{array}$ & 7 & $58 \%$ & 14 & 14 & $(7-28)$ & 165 & 198 & $(115-324)$ & 1 & 1 & 1 \\
\hline $\begin{array}{l}\text { Cats failing to reach } D C \text { within } 4 \text { weeks of } \\
\text { the high dose } G C \text { pulse therapy (eventually } \\
\text { reaching } D\left(\text { with different } T X^{\mathrm{a}} \text { ) }\right.\end{array}$ & 3 & $25 \%$ & 80 & 131 & $(43-269)$ & 465 & 543 & $(465-710)$ & 2 & 2 & 2 \\
\hline $\begin{array}{l}\text { Cats treated with high dose GC pulse } \\
\text { therapy that failed to reach DC (including } \\
\text { other treatment strategies) }\end{array}$ & 2 & $17 \%$ & & & & & & & 3 & 3 & 3 \\
\hline
\end{tabular}

Cumulative dose of glucocorticoids up to the time of disease control was calculated as a prednisolone equivalent for $5 \mathrm{~kg}$ cat. Following estimated steroid equivalency conversions were used: dexamethasone and triamcinolone acetonide about seven times and methylprednisolone 1.3 times more potent than prednisolone [41,42]. Due to the low bioavailability of prednisone in cats [94-96], the equivalency conversion between prednisone and prednisolone could not be determined and, therefore, the single case in which prednisone was used to induce disease control was excluded from the cumulative dose calculation ${ }^{a}$ One of these cats achieved disease control with high-dose pulse glucocorticoid therapy within 43 days (after the second pulse). The remaining cats achieved disease control with other treatment regimens 


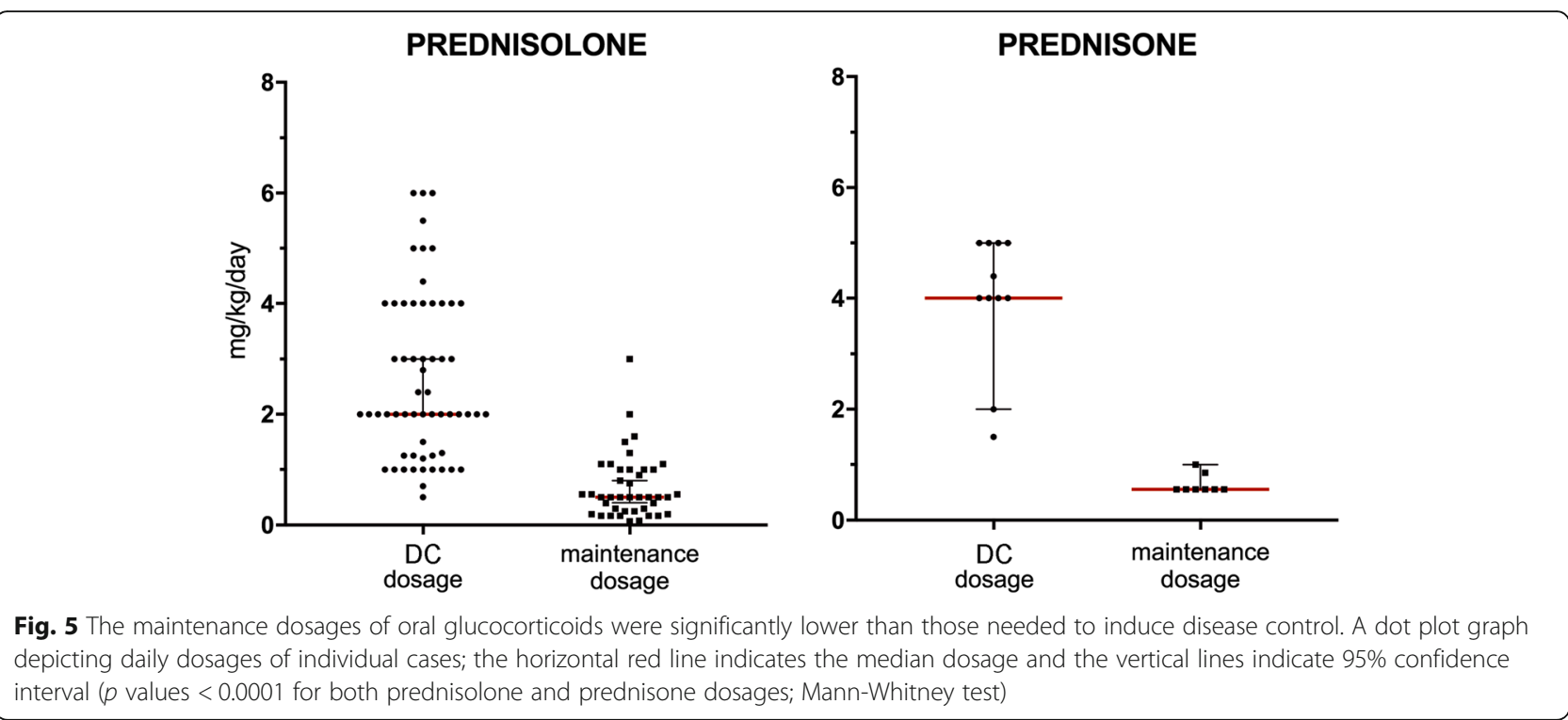

tract disease (2 cats) and transient diabetes mellitus (1 cat)), while the other seven cats received either standard glucocorticoid monotherapy (4 cats) or combination of glucocorticoids and non-steroidal immunosuppressants (3 cats).

Finally, 10 of the 35 cats diagnosed with PF (29\%) died during the follow-up period. Two of the 10 cats (20\%) died due to unrelated causes, and one (10\%) died suddenly for unexplained reasons one year after the diagnosis confirmation. Four of 10 cats $(40 \%)$ were euthanized due to the development of a non-dermatological disease such as chronic renal failure ( 2 cats) and neoplasia (2 cats). Two cats $(20 \%)$ were euthanized after a disease flare up at which point they also suffered with a concurrent non-dermatological disease (diabetes mellitus (1 cat), upper respiratory infection (1 cat)), and one cat (10\%) was euthanized due to the inability to rapidly control the recent flare up. The median time to death was 7 months (mean: 13 months; range: 6-29 months).

\section{Comprehensive literature review}

Treatment and outcome information was available for 140 of 162 cats (86\%). The time of follow-up was reported in 93 cats with a median and mean of 13 and 20 months, respectively (range: 2-84 months). For additional 45 cats, the time of follow-up was reported as median only (9 months; range: 1-54 months) [6]. Disease control was achieved in 132 cats (94\%). The treatment at the time of DC was known in 123 cats, and is summarized in Fig. 4 and Table 4. The time to DC was reported

Table 3 Original case series: Maintenance treatment

\begin{tabular}{|c|c|c|c|c|c|c|}
\hline & \multirow[t]{2}{*}{ \# cats } & \multirow[t]{2}{*}{$\%$ cats } & \multicolumn{3}{|c|}{ Dosages (mg/kg/day) } \\
\hline \multicolumn{2}{|c|}{ Systemic Maintenance Treatment (24 cats total) } & & & Median & Mean & Range \\
\hline \multicolumn{2}{|l|}{ GC monotherapy } & 12 & $50 \%$ & & & \\
\hline \multicolumn{2}{|l|}{ prednisolone } & 7 & $29 \%$ & 0.5 & 0.6 & $(0.2-1.3)$ \\
\hline \multicolumn{2}{|l|}{ triamcinolone } & 2 & $8 \%$ & 0.1 & 0.1 & $(0.05-0.1)$ \\
\hline \multicolumn{2}{|l|}{ dexamethasone } & 3 & $13 \%$ & 0.03 & 0.1 & $(0.03-0.1)$ \\
\hline \multicolumn{2}{|l|}{ Ciclosporin Monotherapy } & 3 & $13 \%$ & 5.3 & 4.8 & $(2.5-6.7)$ \\
\hline \multirow[t]{2}{*}{ ciclosporin + prednisolone } & ciclosporin & 3 & $13 \%$ & 2.5 & 2 & $(0.7-2.5)$ \\
\hline & prednisolone & & & 0.1 & 0.4 & $(0.1-1)$ \\
\hline \multirow[t]{2}{*}{ ciclosporin + triamcinolone } & ciclosporin & 1 & $4 \%$ & 2 & & \\
\hline & triamcinolone & & & 0.05 & & \\
\hline \multicolumn{2}{|l|}{ Chlorambucil Monotherapy } & 2 & $8 \%$ & 0.2 & 0.2 & $(0.15-0.2)$ \\
\hline \multirow[t]{2}{*}{ chlorambucil + prednisolone } & chlorambucil & 3 & $13 \%$ & 0.1 & 0.1 & no range detected \\
\hline & prednisolone & & & 0.5 & 0.7 & $(0.5-1)$ \\
\hline
\end{tabular}


Table 4 Comprehensive literature review: Treatment at the time of disease control

\begin{tabular}{|c|c|c|c|c|c|c|c|c|c|c|}
\hline \multirow[t]{3}{*}{ Treatment Regimen } & \multirow[t]{3}{*}{$\begin{array}{l}\text { Number of Cats } \\
\text { (\%) Treated }\end{array}$} & \multicolumn{3}{|c|}{ Time to Disease Control (days) } & \multicolumn{6}{|c|}{$\begin{array}{l}\text { Drug Dosages at the Time of Disease Control (median, mean } \\
\text { and range }(\mathrm{mg} / \mathrm{kg} / \text { day)) }\end{array}$} \\
\hline & & \multirow[t]{2}{*}{ Median } & \multirow[t]{2}{*}{ Mean } & \multirow[t]{2}{*}{ Range } & \multicolumn{3}{|c|}{ nonsteroidal drug } & \multicolumn{3}{|c|}{ oral glucocorticoid } \\
\hline & & & & & Median & Mean & Range & Median & Mean & Range \\
\hline Oral Glucocorticoid Monotherapy (all) & $76(62 \%)$ & 14 & 21 & $(7-70)$ & & & & & & \\
\hline prednisolone & 49 (40\%) & 14 & 21 & $(7-70)$ & & & & 2 & 2 & $(0.5-6)$ \\
\hline triamcinolone & $15(12 \%)$ & $n r$ & $n r$ & $n r$ & & & & $n r$ & $n r$ & $(0.6-2)$ \\
\hline prednisone & $10(8 \%)$ & $n r$ & $n r$ & $n r$ & & & & 4 & 4 & $(1.5-5)$ \\
\hline dexamethasone & $2(2 \%)$ & $n r$ & $n r$ & $n r$ & & & & $n r$ & $n r$ & $n r$ \\
\hline $\begin{array}{l}\text { Non-Steroidal Immunosuppressants as a } \\
\text { Monotherapy or Combination Therapy }\end{array}$ & $47(38 \%)$ & & & & & & & & & \\
\hline Chlorambucil + Oral Glucocorticoid (all) & $23(19 \%)$ & 32 & 36 & $(14-78)$ & & & & & & \\
\hline chlorambucil + prednisone & $9(7 \%)$ & $n r$ & $n r$ & $n r$ & $n r$ & $n r$ & $n r$ & $n r$ & $n r$ & $n r$ \\
\hline chlorambucil + prednisolone & $8(7 \%)$ & 32 & 36 & (19-78) & 0.1 & 0.2 & $(0.1-0.3)$ & 3 & 4 & $(1.6-8)$ \\
\hline chlorambucil + dexamethasone & $4(3 \%)$ & 28 & 29 & $(14-45)$ & 0.1 & 0.1 & $(0.1-0.2)$ & 0.2 & 0.2 & $(0.1-0.4)$ \\
\hline chlorambucil + triamcinolone & $2(2 \%)$ & $n r$ & $n r$ & $n r$ & $n r$ & $n r$ & $n r$ & $n r$ & $n r$ & $n r$ \\
\hline Ciclosporin Monotherapy & $2(2 \%)$ & 64 & 64 & $(55-73)$ & 5 & 5 & $(5-5.6)$ & & & \\
\hline Ciclosporin + Oral Glucocorticoid (all) & $9(7 \%)$ & 37 & 41 & $(28-67)$ & 5.1 & 5.3 & $(4.4-6.9)$ & & & \\
\hline ciclosporin + dexamethasone & $3(3 \%)$ & 35 & 34 & $(28-38)$ & 5.3 & 5.1 & $(4.4-5.5)$ & 0.2 & 0.2 & $(0.1-0.2)$ \\
\hline ciclosporin + prednisolone & $2(2 \%)$ & 42 & 42 & $(33-50)$ & 5.1 & 5.1 & $(5-5.2)$ & 2.6 & 2.6 & $(2-3.1)$ \\
\hline ciclosporin + triamcinolone & $2(2 \%)$ & 36 & & & 6 & 6 & $(5-6.9)$ & 0.6 & 0.6 & $(0.4-0.9)$ \\
\hline ciclosporin + prednisone & $1(1 \%)$ & 67 & & & 4.8 & & & 3 & & \\
\hline ciclosporin + methylprednisolone & $1(1 \%)$ & 42 & & & $n r$ & & & $n r$ & & \\
\hline Azathioprine + prednisone & $8(7 \%)$ & $\mathrm{nr}$ & 21 & $(14-50)$ & $1.1 \mathrm{mg} / \mathrm{kg}$ & every c & ther day & $4.4 \mathrm{mg} / \mathrm{k}$ & /day & \\
\hline Gold Salts + Oral Glucocorticoids & $5(4 \%)$ & $\mathrm{nr}$ & & & $\begin{array}{l}\text { aurothiog } \\
\text { week }\end{array}$ & lucose: & $.5 \mathrm{mg} / \mathrm{kg} /$ & & & \\
\hline
\end{tabular}

In some cats, disease control was induced with more than one treatment regimen; $\mathrm{nr}$ not reported

in 63 cats with median and mean being 21 and 28 days, respectively (range: 7-78 days). For an additional eight cats, the time to DC was reported as mean only (21 days; range: $14-30$ days) [4]. Times to DC for individual treatment regimens are listed in Table 4 . Three cats were reported to undergo spontaneous remission. In these three cats, an adverse drug reaction was suspected, and discontinuation of all therapeutics given just prior to the development of PF (cimetidine [1 cat], amoxicillin, triamcinolone, neomycin, enilconazole [1 cat] and itraconazole and sulfur dips [1 cat]) led to rapid resolution of all skin lesions $[6,20,23]$.

Glucocorticoid monotherapy was the most common treatment regimen administered at the time of DC (76/ $123 ; 62 \%)$ and used either prednisolone (49 cats), triamcinolone (15 cats), prednisone (10 cats), or dexamethasone (2 cats). Due to missing data, time to DC was reported for prednisolone only, and the median/mean dosages of glucocorticoids administered at the time of DC were calculated for prednisolone and prednisone only (Table 4). In the 15 cats that received triamcinolone, the dosage was reported by the authors as a range only $(0.6-2 \mathrm{mg} / \mathrm{kg} /$ day $)$ [6]. Topical glucocorticoids or tacrolimus were used concurrently with glucocorticoid monotherapy in four cats.

Oral glucocorticoids were frequently combined with chlorambucil $(23 / 123 ; 19 \%)$ or ciclosporin $(9 / 123 ; 9 \%)$, and topical glucocorticoids were used concurrently in seven of these cats (1\% betamethasone cream or $0.015 \%$ triamcinolone spray). In two cats, ciclosporin was used alone to achieve DC. Time to DC and the median/mean daily dosages were reported in 10 chlorambucil- and 10 ciclosporin-receiving cats (Table 4).

Azathioprine combined with oral prednisone (8/123; $7 \%$ ), gold salts (aurothioglucose or aurothiomalate) with oral glucocorticoids $(5 / 123 ; 4 \%)$, and megoestrol acetate monotherapy $(1 / 123 ; 1 \%)$ were used infrequently (Table 4$)$.

Eighteen of the 129 cats (14\%) in which DC was achieved discontinued all systemic drugs. The median and mean time to follow up for these cats was 18 and 23 months, respectively (range: $3.5-84$ months; information available for 15 cats). In the remaining three cats, only the overall median time to follow up was known (9 months). 
Table 5 Comprehensive literature review: Maintenance treatment

\begin{tabular}{|c|c|c|c|c|c|c|}
\hline \multicolumn{2}{|l|}{ Systemic Maintenance Treatment (98 cats total) } & \multirow[t]{2}{*}{ \# cats } & \multirow[t]{2}{*}{$\%$ cats } & \multicolumn{3}{|c|}{ Dosages (mg/kg/day) } \\
\hline & & & & Median & Mean & Range \\
\hline \multicolumn{2}{|l|}{ GC monotherapy } & 62 & $63 \%$ & & & \\
\hline \multicolumn{2}{|l|}{ prednisolone } & 34 & $35 \%$ & 0.5 & 0.6 & $(0.1-1.6)$ \\
\hline \multicolumn{2}{|l|}{ prednisone } & 12 & $12 \%$ & 0.6 & 0.6 & $(0.6-1)$ \\
\hline \multicolumn{2}{|l|}{ triamcinolone } & 13 & $13 \%$ & $n r$ & $n r$ & $0.6-1$ every $1-7$ days \\
\hline \multicolumn{2}{|l|}{ dexamethasone } & 3 & $3 \%$ & $n r$ & $n r$ & $1.5 \mathrm{mg} /$ cat every $2-7$ days \\
\hline \multirow[t]{3}{*}{ glucocorticoids + doxycycline + niacinamide } & doxycycline & 4 & $4 \%$ & $n r$ & $n r$ & $5-13 \mathrm{mg} / \mathrm{kg}$ once to twice daily \\
\hline & niacinamide & & & $n r$ & $n r$ & $25-44 \mathrm{mg} / \mathrm{kg}$ once to twice daily \\
\hline & $\begin{array}{l}\text { prednisolone/ prednisolone } \\
\text { equivalent }\end{array}$ & & & 0.4 & 0.4 & $(0.3-0.5)$ \\
\hline \multicolumn{2}{|l|}{ Ciclosporin Monotherapy } & 6 & $6 \%$ & 2.5 & 3.5 & $(1.7-6.7)$ \\
\hline \multicolumn{2}{|l|}{ Ciclosporin (in combination with GC) } & 2 & $2 \%$ & 4.2 & 4.2 & $(3.5-5)$ \\
\hline \multicolumn{2}{|l|}{ Chlorambucil Monotherapy } & 7 & $7 \%$ & 0.1 & 0.1 & $(0.1-0.2)$ \\
\hline \multicolumn{2}{|l|}{ Chlorambucil (in combination with GC) } & 11 & $11 \%$ & 0.1 & 0.1 & $(0.1-0.2)$ \\
\hline \multicolumn{2}{|l|}{ Gold Salts monotherapy } & 3 & $3 \%$ & $n r$ & $n r$ & $0.5-1 \mathrm{mg} / \mathrm{kg}$ once to twice weekly \\
\hline \multicolumn{2}{|l|}{ Gold Salts (in combination with GC) } & 3 & $3 \%$ & $n r$ & $n r$ & \\
\hline
\end{tabular}

nr not reported

A maintenance regimen information was known for 98 of the 140 cats (70\%) (Table 5). Oral glucocorticoid monotherapy was used most frequently $(62 / 98 ; 63 \%)$, and included prednisolone (34/98; 35\%), prednisone (12/ $98 ; 12 \%)$, triamcinolone $(13 / 98 ; 13 \%)$ and dexamethasone $(3 / 98 ; 3 \%)$. The median/mean daily dosages and ranges are reported in Table 5. In case of triamcinolone and dexamethasone, the maintenance dosages were reported only as a range (triamcinolone: $0.6-1 \mathrm{mg} / \mathrm{kg}$ every 1-7 days; dexamethasone: $1.5 \mathrm{mg} / \mathrm{cat}$ every $2-7$ days) [6].

Oral glucocorticoids were combined with doxycycline and niacinamide $(4 / 98 ; 4 \%)$, chlorambucil $(11 / 98 ; 11 \%)$, ciclosporin $(2 / 98 ; 2 \%)$ or gold salts $(3 / 98 ; 3 \%)$ (Table 5$)$. The three latter drugs were also able to maintain the PF in remission when used as a monotherapy $(16 / 98 ; 16 \%)$ (Table 5).

Disease flare ups were reported in 55 of the 123 cats (45\%) for which this information was provided, and they were most frequently associated with either a reduction of drug dosage or discontinuation of a treatment. In two cats, in which a drug-triggered PF was suspected, the disease relapsed after repeated administration of the offending drug (cimetidine (1 cat) and doxycycline (1 cat)) $[20,22]$.

Adverse effects related to treatment were reported in 39 of the 119 cats (33\%) (cats with spontaneous remission of their disease, and those without relevant information were excluded). The most common adverse effects reported in cats receiving glucocorticoids included polyphagia and weight gain (8 cats), polyuria/ polydipsia (7 cats), urinary tract infections (4 cats), hyperglycemia (2 cats), diarrhea or melena (3 cats), skin atrophy and skin fragility (2 cats), lethargy and anorexia (3 cats), pancreatitis (1 cat), and demodicosis (1 cat). Adverse effects reported in cats receiving chlorambucil alone or in combination with glucocorticoids included polyuria/polydipsia (4 cats), anorexia (3 cats), leukopenia ( 2 cats), thrombocytopenia ( 2 cats), anemia (1 cat) and increased liver enzymes (1 cat). Cats receiving ciclosporin alone or in combination with glucocorticoids developed disseminated mycobacteriosis (2 cats), diarrhea (1 cat) and hypertrichosis (1 cat). The use of azathioprine at $1.1 \mathrm{mg} / \mathrm{kg}$ every other day dosage was associated with leukopenia and neutropenia in the majority of cats $(5 / 8$ cats) receiving this medication. A corneal ulcer (1 cat) and skin abscess $(1 \mathrm{cat})$ were observed in cats managed with gold salts and glucocorticoids, while the cat managed with megoestrol acetate developed demodicosis.

Nine of the 140 cats $(6 \%)$ with known treatment and outcome died during the follow up period for variable reasons. One cat was euthanized immediately after the diagnosis confirmation and two shortly after due to treatment side effects or lack of DC. The rest of them developed non-dermatological diseases such as lymphoma (2 cats), disseminated mycobacteriosis (1 cat), pulmonary oedema and seizures (1 cat), cardiac arrest (1 cat) and severe gastrointestinal issues of unknown cause (1 cat). Most publications did not provide information about the time between the diagnosis confirmation and death.

\section{Discussion}

The majority of publications about feline PF found between 1950 and 2016 only describe one to two cases. 
Our goal was to review the published literature and, with 35 original cases, provide a concise overview of what is currently known about feline PF.

Based on this review, pemphigus foliaceus affects middle aged cats (mean age of onset approximately 7 years), which is similar to dogs (4-6 years) and humans (40-60 years) [3, 44]. Domestic short-haired and Siamese cats were most commonly affected; however, a true breed predisposition could not be confirmed due to the nature of this study and the lack of population data for comparison. In dogs, a breed predisposition has been confirmed in Akitas and chow-chows, while in people, once endemic PF is excluded, no race/ethnicity predisposition has been observed [3, 44]. Although females marginally outnumbered males, sex predisposition could similarly not be confirmed. In canine and human PF, no sex predilection has been reported [3, 44].

Multiple triggers have been associated with development of PF in humans and dogs including drugs, pesticides/insecticides, neoplasia, immunization, infection, ultra-violet light, hormones and stress [3, 44-48]. Two cats with thymoma and concurrent PF have been published [32, 35]. Thymoma has been associated with a variety of autoimmune diseases in humans, cats and dogs, including different pemphigus variants [12, 4952], and, therefore, it is possible that the PF in these cats was also related to the tumor's aberrant effect on the immune system [53-55].

Variety of drugs have been associated with development of PF or PF-like disease in humans and dogs (reviewed in $[45,56]$ ). This review identified eight cats in which drugs were proposed to be involved in the PF development, though only four of these cases would qualify as a probable drug reaction based on a retrospectively applied Naranjo drug reaction probability scale $[6,20,22,23]$. Interestingly, one of these cats experienced a relapse of PF after reintroduction of doxycycline; a drug originally suspected to have been the trigger [22]. Considering the known anti-inflammatory properties of tetracycline antibiotics, and their use in managing some autoimmune skin diseases, including pemphigus, in humans and animals, this possible association is very unusual [57-59].

One cat with PF had concurrent leishmaniosis [28]. Similarly, PF and PF-like disease have been associated with canine and human leishmaniosis [60-62]. Whether the infection is the trigger for PF in these cases remains unknown. Interestingly, leishmaniosis and other vector-borne diseases had been hypothesized to play a role in human endemic PF in Brazil, but these have been recently replaced by a theory involving a sand fly salivary antigen molecular mimicry $[62,63]$.

In majority of cats, skin lesions involved more than one body region with head/face, claw folds and pawpads being the most frequently affected body sites (Figs. 2 and 3). Claw folds were the only affected body site in $11 \%$ of cats, and, therefore, PF should be considered as a relevant differential diagnosis in cats with erosive, exudative and/or crusting paronychia affecting the majority of digits. The periareolar region was affected in $10 \%$ of all cats for which this detail was provided, though there was difference between the numbers reported in the literature review (7\%) and the original case series (20\%). Similarly, the involvement of the perianal and/or perigenital region was more commonly mentioned in the original cases series (11\%) than in the literature review (3\%). These differences between the historically published literature and the original cases could be due to the failure to notice lesions in these sites or report these sites as a specific body region (e.g. periareolar region reported as a ventrum) or due to a true variation in incidence. Non-dermatological signs such as fever, lethargy and anorexia were reported in about half of all cats. In dogs, only two studies provide information on systemic signs, with one reporting one third of dogs to be lethargic [64], and the other mentioning that systemic signs usually accompanied only severe and more generalised disease [1]. In contrast, about half of dogs with an insecticide-triggered PF were reported to exhibit non-dermatological signs [46-48].

Feline PF has a good prognosis. The majority of cats $(\sim$ $90 \%$ on average) achieved DC in less than one month. This is in contrast to canine PF in which DC is achieved in a notably lower percentage of dogs $(52 \%$ based on the largest case series) [65]. Additionally, some of the older studies reported "successful" treatment of PF in 53 and $88 \%$ of dogs $[1,64]$, but these studies did not define what the "successful" management meant in terms of the DC. Also in contrast to cats, dogs with PF require notably longer time to DC (based on the largest case series, the average times to DC with glucocorticoid monotherapy and with glucocorticoids and azathioprine combination were seven and 12 months, respectively) [65].

Glucocorticoids alone or in combination with nonsteroidal immunosuppressants are the most commonly used drug class for the induction of DC; prednisolone monotherapy being one of the most common treatment strategies. According to the existing literature, the recommended dosages of prednisolone for feline PF vary from 2 to $6.6 \mathrm{mg} / \mathrm{kg} /$ day $[1,8,66]$. The analysis of the original cases and the literature review supports the effectiveness of dosages at the lower end of that recommended range. Information about the dosages of other oral glucocorticoids such as dexamethasone and triamcinolone was too limited to draw any meaningful conclusions.

A high-dose oral glucocorticoid pulse therapy following the principles described in PF-affected dogs [43] was 
used in 12 cats in an effort to achieve a faster DC and/ or reduced overall cumulative dose of glucocorticoids. Interestingly, when the time to DC, the cumulative dose of glucocorticoids and the number of cats reaching DC within a month were compared between cats treated with high-dose glucocorticoid pulse therapy and standard glucocorticoid monotherapy, there was no obvious benefit of the former therapy. This perceived lack of added benefit of the pulse therapy could be explained by the observation that cats with PF respond to standard treatment protocols relatively rapidly. It is also possible that, due to the lower number of high-affinity glucocorticoid receptors in feline liver and skin compared to dogs [67], the dosage of prednisolone in the high-dose glucocorticoid pulse therapy for cats should have exceeded the $10 \mathrm{mg} / \mathrm{kg}$ dosage used in dogs [43]. Indeed, dosages of prednisolone as high as $8.8 \mathrm{mg} / \mathrm{kg} /$ day can be found in the literature and are recommended as part of standard immunosuppressive protocols (reviewed in [41]).

Ciclosporin and chlorambucil have been used by veterinary dermatologists to manage feline PF for years. Both drugs have been used also in canine PF [3], although a variable efficacy has been reported in case of ciclosporin [68-70]. Generally accepted dosages of ciclosporin and chlormabucil for management of autoimmune disorders in cats range between $5-10 \mathrm{mg} / \mathrm{kg} /$ day and $0.1-0.2 \mathrm{mg} /$ $\mathrm{kg} /$ day or every other day, respectively [71]. These generally-accepted dosages were supported by those extrapolated from the original cases and the literature review here. The unusually long time to $\mathrm{DC}$ in the original case series cats treated with non-steroidal immunosuppressants (average time to DC: 105 days) might give an impression that cats receiving non-steroidal immunosuppressants alone or in combination with glucocorticoids require longer time to DC than those treated with glucocorticoid monotherapy. However, this longer time to DC with this treatment strategy was not observed in cats from the literature review (average time to DC: 41 days). The notably longer time to DC in cats from the former group is likely related to the standard of care used by clinicians contributing cases to the study. Indeed, the preferred treatment strategy at both institutions relies traditionally on glucocorticoid monotherapy, and non-steroidal drugs are only used when DC cannot be achieved in a timely fashion.

Most cats included in this study required long-term treatment and complete drug withdrawal with prolonged disease remission was reported only in the minority (17 and $14 \%$ in original cases and literature review, respectively). A similar outcome has been reported in dogs with naturally occurring PF in which complete treatment discontinuation was possible in 7 to $22 \%$ of cases (reviewed in [3]). The majority of cats requiring a long-term treatment received glucocorticoids at lower (anti-inflammatory) dosages than those used for induction of DC. Indeed, the maintenance dosages of prednisolone and prednisone were significantly lower than those at the time of DC ( $p$ value $<0.0001$; Mann-Whitney test; Fig. 5). Statistical comparison for dexamethasone and triamcinolone dosages was not possible due to the low number of treated cats. Other treatments used for disease maintenance included ciclosporin or chlorambucil alone, or in combination with glucocorticoids. In most cats, the maintenance ciclosporin dosages were $25-50 \%$ lower than the initial dosages, though the range varied greatly (range: 0.7-6.7 $\mathrm{mg} / \mathrm{kg} /$ day; every other day dosing was common). The maintenance dosages of chlorambucil varied between 0.1 and $0.2 \mathrm{mg} / \mathrm{kg} /$ day (every other day dosing was common). Topical glucocorticoids were useful in managing some cats alone or in combination with systemic treatment.

Despite the maintenance treatment, disease flare ups were frequent (77 and $45 \%$ in original cases and literature review, respectively), and usually followed a dose reduction or an attempt to discontinue treatment. In two cats with suspected drug reaction, a disease flare up followed shortly after re-introduction of the drug [20, 22].

Adverse effects related to the treatment were reported in one third of cats treated for PF. Diabetes mellitus, urinary tract infections and hepatopathy were the more severe signs usually reported in associated with glucocorticoids, while bone marrow suppression was more common in chlorambucil and azathioprine treated cats. The rapid onset of myelosuppression in the azathioprine treated cats was likely related to the used dosage (1.1 $\mathrm{mg} / \mathrm{kg}$ every other day) and the lower level of thiopurine S-methyltransferase in this species, an enzyme responsible for the S-methylation of thiopurine drugs and inactivation of the cytotoxic 6-mercaptopurine [17]. Indeed, anecdotally, lower dosages (e.g. $0.3 \mathrm{mg} / \mathrm{kg}$ every other day) have been reported to be successful in managing other immune-mediated diseases [72].

Death or euthanasia directly related to the PF diagnosis (e.g. unwillingness to treat a cat with this condition) or a treatment failure (e.g. inability to induce DC, relapsing disease) or due to the occurrence of additional health issues, which might or might not have been related to the treatment, was reported in $10 \%$ of cats. This outcome appears to be markedly better than that reported for canine PF in which, based on one study, $42 \%$ of dogs were euthanized because of the lack of response to treatment, poor quality of life or due to treatment-associated adverse effects [73].

Finally, this retrospective case review has inherent limitations related to its predominantly clinical observational data, i.e. descriptions of skin lesion distributions, clinical signs, treatment responses, etc. Descriptions are only as detailed or accurate as reported, were made by different observers and were not collected by a standardized method. 
In summary, feline PF is a pustular disease with secondary erosions and crusts, which usually predominate as a lesion type. The diagnosis of feline PF remains based on confirmation of subcorneal pustular disease, a rare lesion type in cats, and of its acantholytic nature. The majority of cats with PF exhibit lesions on the face and feet, though a subset of cats may exhibit lesions exclusively on the claw folds. Analysis of original cases herein suggests periareolar and perianal/perigenital area involvement to be more common than previously reported. Non-dermatological signs such as lethargy, fever and/or anorexia have been reported in more than half of cats with active disease. The prognosis of feline PF is good as the majority of cats rapidly achieve DC even with a simple immunosuppression protocol involving glucocorticoids monotherapy. However, well-designed studies comparing steroidal and non-steroidal treatment protocols are lacking. Most PF-affected cats require long-term treatment and, like other autoimmune disease, feline PF has a tendency to relapse spontaneously or with treatment changes. Owners should be informed and prepared for these circumstances, which may reduce the risk of euthanasia in case of disease relapse and improve treatment compliance.

\section{Abbreviations}

DC: Disease control; PF: Pemphigus foliaceus

\begin{abstract}
Acknowledgements
The authors appreciate the BMC Veterinary Research editorship for the waiving of the page charges for this collection of articles. The authors would like to thank Dr. Keith Linder for reviewing the manuscript, and Drs. Aurore Laprais, Marcy Murphy, Thierry Olivry, Michael Rossi and Heng L. Tham for allowing us to include their cases.
\end{abstract}

\section{Funding}

None.

\section{Availability of data and materials}

This article being a review of published information, data sharing is not applicable as no datasets were generated or analysed.

\section{Authors' contributions}

PB designed the concept of this article, perform the literature search and primary cases analysis and wrote the manuscript; MB provided data for the original case series, reviewed the data from the literature search and primary cases and reviewed the final manuscript. Both authors read and approved the final manuscript.

Ethics approval and consent to participate Not applicable.

\section{Consent for publication}

Not applicable.

\section{Competing interests}

The authors declare that they have no competing interests.

\section{Publisher's Note}

Springer Nature remains neutral with regard to jurisdictional claims in published maps and institutional affiliations.

\section{Author details}

'Department of Clinical Sciences, College of Veterinary Medicine, North Carolina State University, 1060 William Moore Drive, Raleigh, NC 27607, USA. ${ }^{2}$ Center for Comparative Medicine and Translational Research, North Carolina State University, Raleigh, NC, USA. ${ }^{3}$ Murdoch University Veterinary Hospital, School of Veterinary and Biomedical Science, Murdoch University, Murdoch, WA, Australia.

Received: 18 April 2018 Accepted: 5 December 2018

Published online: 09 January 2019

\section{References}

1. Scott DW, Walton DL, Slater MR. Immune-mediated dermatoses in domestic animals: ten years after - part I. Comp Cont Educ Pract. 1987;9:424-35.

2. Scott DW, Miller WH, Erb HN. Feline dermatology at Cornell University: 1407 cases (1988-2003). J Feline Med Surg. 2013;15(4):307-16.

3. Olivry T. A review of autoimmune skin diseases in domestic animals: I superficial pemphigus. Vet Dermatol. 2006;17(5):291-305.

4. Caciolo PL, Nesbitt GH, Hurvitz Al. Pemphigus foliaceus in eight cats and results of induction therapy using azathioprine. JAAHA. 1984;20:571-7.

5. Day MJ, Hanlon L, Powell LM. Immune-mediated skin disease in the dog and cat. J Comp Pathol. 1993;109(4):395-407.

6. Preziosi DE, Goldschmidt MH, Greek JS, Jeffers JG, Shanley KS, Drobatz K, Mauldin EA. Feline pemphigus foliaceus: a retrospective analysis of 57 cases. Vet Dermatol. 2003;14(6):313-21.

7. Irwin KE, Beale KM, Fadok VA. Use of modified ciclosporin in the management of feline pemphigus foliaceus: a retrospective analysis. Vet Dermatol. 2012;23(5):403-9.

8. Simpson DL, Burton GG. Use of prednisolone as monotherapy in the treatment of feline pemphigus foliaceus: a retrospective study of 37 cats. Vet Dermatol. 2013;24(6):598-601.

9. Gross TL, Ihrke PJ, Walder EJ, Affolter VK. Pustular diseases of the epidermis (superficial pustular dermatophytosis). In: Skin diseases of the dog and cat. 2nd ed. Oxford: Blackwell Science Ltd.; 2005. p. 11-3.

10. Scott DW. Feline dermatology 1900-1978: a monograph. J Am Anim Hosp Assoc. 1980;16(3):331-459.

11. Gross TL, Ihrke PJ, Walder EJ, Affolter VK. Pustular diseases of the epidermis (impetigo). In: Skin diseases of the dog and cat. 2nd ed. Oxford: Blackwell Science Ltd.; 2005. p. 4-6.

12. Olivry T, Linder KE. Dermatoses affecting desmosomes in animals: a mechanistic review of acantholytic blistering skin diseases. Vet Dermatol. 2009;20(5-6):313-26.

13. Manning TO, Scott DW, Smith CA, Lewis RM. Pemphigus diseases in the feline: seven case reports and discussion. JAAHA. 1982;18:433-43.

14. Scott DW, Manning TO, Smith CA, Lewis RM. Pemphigus and pemphigoid in dogs, cats and horses. Ann N Y Acad Sci. 1983;420:353-60.

15. Rosenkrantz WS. Pemphigus: current therapy. Vet Dermatol. 2004;15(2):90-8.

16. White SD, Rosychuk RA, Outerbridge CA, Fieseler KV, Spier S, Ihrke PJ, Chapman PL. Thiopurine methyltransferase in red blood cells of dogs, cats, and horses. J Vet Intern Med. 2000;14(5):499-502.

17. Foster AP, Shaw SE, Duley JA, Shobowale-Bakre EM, Harbour DA. Demonstration of thiopurine methyltransferase activity in the erythrocytes of cats. J Vet Intern Med. 2000;14(5):552-4.

18. Murrell DF, Pena S, Joly P, Marinovic B, Hashimoto T, Diaz LA, Sinha AA, Payne AS, Daneshpazhooh M, Eming R, Jonkman MF, Mimouni D, Borradori L, Kim SC, Yamagami J, Lehman JS, Saleh MA, Culton DA, Czernik A, Zone JJ, Fivenson D, Ujiie H, Wozniak K, Akman-Karakas A, Bernard P, Korman NJ, Caux F, Drenovska K, Prost-Squarcioni C, Vassileva S, Feldman RJ, Cardones AR, Bauer J, loannides D, Jedlickova H, Palisson F, Patsatsi A, Uzun S, Yayli S, Zillikens D, Amagai M, Hertl M, Schmidt E, Aoki V, Grando SA, Shimizu H, Baum S, Cianchini G, Feliciani C, Iranzo P, Mascaro JM Jr, Kowalewski C, Hall R, Groves R, Harman KE, Marinkovich MP, Maverakis E, Werth VP. Diagnosis and Management of Pemphigus: recommendations by an International Panel of Experts. J Am Acad Dermatol. 2018; [Epub ahead of print].

19. Carlotti D. Cas clinique: pemphiqus foliaceus chez un chat. Point Vet. 1984; 16:97-9.

20. McEwan NA, McNeil PE, Kirkham D, Sullivan M. Drug eruption in a cat resembling pemphigus foliaceus. J Small Anim Pract. 1987;28(8):713-20.

21. Andersen HK, Kristensen F. Pemphiqus foliaceus hos kat. Dansk VetTidsskr. 1988;71:1020-7. 
22. Prelaud P, Mialot M, Kupfer B. Accident cutane medicamenteux evoquant un pemphigus foliace chez un chat. Point Vet. 1991;23:313-8.

23. Affolter VK, Tscharner CV. Cutaneous drug reactions: a retrospective study of histopathological changes and their correlation with the clinical cisease. Vet Dermatol. 1993;4(2):79-86.

24. Page N, Paradis M. Quel est votre diagnostic? Med Vet Que. 1997:27:72-(81-82)

25. Bensignor E, Carlotti D. A propos de quatre cas de pemphigus foliace avec atteinte exclusive des coussinets. Prat Med Chir Anim Comp. 1997;32:481-90.

26. Larsson CE, Otsuka M, Amaral RC, Michalany NS, Franchini ML. Pemphigus foliaceus - first case report in a cat (Sao Paulo, Brazil). Clin Vet. 2000;5:29-32.

27. Barrs VR, Beatty JA, Kipar A. What is your diagnosis? J Small Anim Pract. 2003;44(251):286-7.

28. Rufenacht S, Sager H, Muller N, Schaerer V, Heier A, Welle MM, Roosje PJ. Two cases of feline leishmaniosis in Switzerland. Vet Rec. 2005;156(17):542-5.

29. Spilmont C, Ponce F. Un cas de pemphigus foliace chez un chat. Point Vet. 2005;36:58-62.

30. Bordeau W. A case of pemphigus foliaceus in a cat. Point Vet. 2005 36(259):70.

31. Albuquerque ACD. Penfigo foliaceo em gato - relato de caso; 2006

32. Biaggi AF, Erika U, Biaggi CP, Taboada P, Santos R. Pemphigus foliaceus in cat: two cases report. 34th World Small Animal Veterinary Association Congress, São Paulo, Brazil, 21-24 July 2009.

33. de Bellis F, Bond R, Lloyd DH. Successful treatment ofo recalcitrant pemphigus foliaceus in a cat using hydrocortisone aceponate spray [abstract]. Vet Dermatol. 2008;19(Suppl 1):80.

34. Peterson A, McKay L. Applied dermatology - crusty cats: feline pemphigus foliaceus. Compend Contin Educ Vet. 2010;32(5):E1-4.

35. Coyner KS. Dermatology how would you handle this case? Vet Med. 2011; 106(6):280-3.

36. Neuber A, Shaw SC. Topical application of hydrocortisone aceponate spray (Cortavance ${ }^{\circledast}$ ) for the treatment of pemphigus foliaceus in a cat. Wien Tierarztl Monatsschr. 2011;98(7):156-9.

37. Shinohara $Y$, Kai K, Kawase $Y$, Nagata M. A case report on combined treatment by triamcinolone and cyclosporine for feline pemphigus foliaceus. Nippon Juishikai Zasshi. 2012;65(4):299-302.

38. Imamichi S. Pemphigus foliaceus-like eruption following feline triple vaccine in a 3-month-old cat. Jpn J Vet Dermatol. 2013;19(2):69-73.

39. Jark PC, Estanislau C, Rondelli MCH, Fabris VE, Tinucci-Costa M, Lourenço MLG, Machado LH. Pemphigus foliaceus in a cat: case report. / Pênfigo foliáceo em um felino: relato de caso. Vet Zootec. 2014;21(4):543-9.

40. Salzo P, Daniel A, Silva P. Probable pemphigus foliaceus-like rug reaction in a cat [abstract]. Vet Dermatol. 2014;25:392.

41. Lowe AD, Campbell KL, Graves T. Glucocorticoids in the cat. Vet Dermatol. 2008;19(6):340-7.

42. Rohatagi S, Hochhaus G, Mollmann H, Barth J, Galia E, Erdmann M, Sourgens $\mathrm{H}$, Derendorf H. Pharmacokinetic and pharmacodynamic evaluation of triamcinolone acetonide after intravenous, oral, and inhaled administration. J Clin Pharmacol. 1995;35(12):1187-93.

43. Bizikova P, Olivry T. Oral glucocorticoid pulse therapy for induction of treatment of canine pemphigus foliaceus - a comparative study. Vet Dermatol. 2015:26(5):354-8 e76-7.

44. James KA, Culton DA, Diaz LA. Diagnosis and clinical features of pemphigus foliaceus. Dermatol Clin. 2011;29(3):405-12 viii.

45. Brenner S, Mashiah J, Tamir E, Goldberg I, Wohl Y. PEMPHIGUS: an acronym for a disease with multiple etiologies. Skinmed. 2003:2(3):163-7.

46. Oberkirchner U, Linder KE, Dunston S, Bizikova P, Olivry T. Metaflumizoneamitraz (Promeris)-associated pustular acantholytic dermatitis in 22 dogs: evidence suggests contact drug-triggered pemphigus foliaceus. Vet Dermatol. 2011;22(5):436-48

47. Bizikova P, Linder KE, Olivry T. Fipronil-amitraz-S-methoprene-triggered pemphigus foliaceus in 21 dogs: clinical, histological and immunological characteristics. Vet Dermatol. 2014:25(2):103-11 e29-30.

48. Bizikova P, Moriello KA, Linder KE, Sauber L. Dinotefuran/pyriproxyfen/ permethrin pemphigus-like drug reaction in three dogs. Vet Dermatol. 2015; 26(3):206-8 e45-6.

49. Takeshita K, Amano M, Shimizu T, Oyamada Y, Abiko T, Kobayashi K, Futei $Y$, Amagai M, Kuramochi S, Asano K, Yamaguchi K. Thymoma with pemphigus foliaceus. Intern Med. 2000;39(9):742-7.

50. Ruocco E, Wolf R, Ruocco V, Brunetti G, Romano F, Lo Schiavo A. Pemphigus: associations and management guidelines: facts and controversies. Clin Dermatol. 2013;31(4):382-90.
51. Tsuchisaka A, Kaneko S, Imaoka K, Ota M, Kishimoto K, Tomaru U, Kasahara M, Ohata C, Furumura M, Takamori S, Morita E, Hashimoto T. Presence of autoimmune regulator and absence of desmoglein 1 in a thymoma in a patient with pemphigus foliaceus. Br J Dermatol. 2015;173(1):268-71.

52. Hill PB, Brain P, Collins D, Fearnside S, Olivry T. Putative paraneoplastic pemphigus and myasthenia gravis in a cat with a lymphocytic thymoma. Vet Dermatol. 2013;24(6):646-9 e163-4

53. Shelly S, Agmon-Levin N, Altman A, Shoenfeld Y. Thymoma and autoimmunity. Cell Mol Immunol. 2011:8(3):199-202.

54. Holbro A, Jauch A, Lardinois D, Tzankov A, Dirnhofer S, Hess C. High prevalence of infections and autoimmunity in patients with thymoma. Hum Immunol. 2012;73(3):287-90.

55. Rottenberg S, von Tscharner C, Roosje PJ. Thymoma-associated exfoliative dermatitis in cats. Vet Pathol. 2004;41(4):429-33.

56. Voie KL, Campbell KL, Lavergne SN. Drug hypersensitivity reactions targeting the skin in dogs and cats. J Vet Intern Med. 2012;26(4):863-74.

57. McCarty M, Fivenson D. Two decades of using the combination of tetracycline derivatives and niacinamide as steroid-sparing agents in the management of pemphigus: defining a niche for these low toxicity agents. J Am Acad Dermatol. 2014;71(3):475-9.

58. Perret $L$, Tait CP. Non-antibiotic properties of tetracyclines and their clinical application in dermatology. Australas J Dermatol. 2014;55(2):111-8.

59. White SD, Rosychuk RA, Reinke SI, Paradis M. Use of tetracycline and niacinamide for treatment of autoimmune skin disease in 31 dogs. J Am Vet Med Assoc. 1992;200(10):1497-500.

60. Colombo S, Abramo F, Borio S, Albanese F, Noli C, Dedola C, Leone F. Pustular dermatitis in dogs affected by leishmaniosis: 22 cases. Vet Dermatol. 2016:27(1):9-e4.

61. Ginel PJ, Mozos E, Fernandez A, Martinez A, Molleda JM. Canine pemphigus foliaceus associated with leishmaniasis. Vet Rec. 1993;133(21):526-7.

62. Diaz LA, Arteaga LA, Hilario-Vargas J, Valenzuela JG, Li N, Warren S, Aoki V, Hans-Filho G, Eaton D, dos Santos V, Nutman TB, de Mayolo AA, Qaqish BF, Sampaio SA, Rivitti EA, Cooperative Group on Fogo Selvagem Research. Anti-desmoglein-1 antibodies in onchocerciasis, leishmaniasis and Chagas disease suggest a possible etiological link to fogo selvagem. J Invest Dermatol. 2004:123(6):1045-51.

63. Qian Y, Jeong JS, Abdeladhim M, Valenzuela JG, Aoki V, Hans-Filhio G, Rivitti EA, Diaz LA. IgE anti-LJM11 sand fly salivary antigen may herald the onset of fogo selvagem in endemic Brazilian regions. J Invest Dermatol. 2015;135(3): 913-5.

64. Ihrke PJ, Stannard AA, Ardans AA, Griffin CE. Pemphigus foliaceus in dogs: a review of 37 cases. J Am Vet Med Assoc. 1985:186(1):59-66.

65. Mueller RS, Krebs I, Power HT, Fieseler KV. Pemphigus foliaceus in 91 dogs. J Am Anim Hosp Assoc. 2006;42(3):189-96.

66. Miller WH, Griffin CE, Campbell KL. Autoimmune and immune-mediated dermatoses. In: Anonymous, editor. Muller and Kirk's Small Animal Dermatology. 7th ed. Missouri: Elsevier; 2013. p. 432-500.

67. van den Broek AH, Stafford WL. Epidermal and hepatic glucocorticoid receptors in cats and dogs. Res Vet Sci. 1992;52(3):312-5.

68. Olivry T, Rivierre C, Murphy KM. Efficacy of cyclosporine for treatment induction of canine pemphiqus foliaceus. Vet Rec. 2003:152(2):53-4.

69. Forsythe P, Paterson S. Ciclosporin 10 years on: indications and efficacy. Vet Rec. 2014;174(Suppl 2):13-21.

70. Anonymous. Is ciclosporin an effective treatment for canine pemphigus foliaceus? Vet Rec. 2017:181(21):566-8.

71. Miller WH, Griffin CE, Campbell KL. Muller \& Kirk's Small Animal Dermatology (7th Edition): 2nd Edition. St. Louis: Elsevier; 2013.

72. Willard MD. Feline inflammatory bowel disease: a review. J Feline Med Surg. 1999:1(3):155-64.

73. Gomez SM, Morris DO, Rosenbaum MR, Goldschmidt MH. Outcome and complications associated with treatment of pemphigus foliaceus in dogs: 43 cases (1994-2000). J Am Vet Med Assoc. 2004;224(8): 1312-6.

74. Scott DW, Miller WH, Lewis RM, Manning TO, Smith CA. Pemphigus erythematosus in the dog and cat. JAAHA. 1980;16:815-23.

75. Faircloth JC. A practitioner case-report: pemphigus erythematosus in a cat. Feline Pract. 1982;12:31-3.

76. Scott DW, Walton DK, Lewis RM, Smith CA. Pitfalls in immunofluorescence testing in dermatology. II. Pemphigus-like antibodies in the cat, and direct immunofluorescence testing of normal dog nose and lip. Cornell Vet. 1983. 73:275-9. 
77. Day MJ, Penhale WJ. Immunodiagnosis of autoimmune skin disease in the dog, cat and horse. Aust Vet J. 1986;63(3):65-8.

78. Mason KV, Day MJ. A pemphigus foliaceus-like eruption associated with the use of ampicillin in a cat. Aust Vet J. 1987;64(7):223-4.

79. Rosenkrantz WS, Griffin CE, Barr RJ. Clinical evaluation of cyclosporine in animal models with cutaneous immune-mediated disease and epitheliotropic lymphoma. JAAHA. 1989;25:377-84.

80. Berrington AJ, Clark EG, Haines DM. Pemphigus foliaceus; a common cause of feline pododermatitis [abstract]. Orlando: ACVP Annual Meeting; 1991.

81. Kristensen F, Bjerring Mehl $\mathrm{N}$. The use of gold in the treatment of autoimmune diseases in the dog and cat. EJCAP. 1992;3:37-9.

82. Kofod H. Pemphigus foliaceus in a cat. Vet Rec. 1993;132:64-5.

83. Cagnasso A, Dotta U, Abate O, Castagnaro M. Pemfigo foliaceo nel gatto: descrizione di in caso. Acta Med Vet. 1995;41:243-51.

84. Noli C, Koeman JP, Willemse T. A retrospective evaluation of adverse reactions to trimethoprim-sulphonamide combinations in dogs and cats. Vet Q. 1995;17(4):123-8.

85. Day MJ. Review of thymic pathology in 30 cats and 36 dogs. J Small Anim Pract. 1997;38(9):393-403.

86. Scott DW, Miller WH. Idiosyncratic cutaneous adverse drug reactions in the cat: literature review and report of 14 cases (1990-1996). Feline Pract. 1998; 26(4):10-5.

87. Alhaidari Z. Pemphigus foliace chez une chatte europeenne de 4 ans. Ann Dermatol Venereol. 2000;127:306

88. Fabbrini F. Pemfigo eritematoso in un gatto persiano. Quaderni Dermatol. 2000;5:27-9.

89. Preziosi DE, Goldschmidt MH, Greek JS, Jeffers JG, Shanley KS, Mauldin EA. Feline pemphigus foliaceus: a retrospective analysis of 57 cases [abstract]. Vet Dermatol. 2003;14:233.

90. Chapelin F, Cadiergues MC, Delverdier M, Petit C, Reynolds B, Franc M. Feline pemphigus foliaceus : a clinical case and litterature review. Rev Med Vet. 2004;2:87-91.

91. Kaimio M, Saijonmaa-Koulumies L. Pemphigus in dog and cat - literature review and a case report. / Pemfigus koiralla ja kissalla - kirjallisuuskatsaus ja tapausselostus. Suomen Eläinläkääilehti. 2007:113(1):7-15.

92. Cogny M. Pemphigus foliaceus in a cat. Point Vet. 2009;40(293):38.

93. Irwin KE, Beale KM, Fadok VA. Comparison of modified ciclosporin to chlormabucil in the management of feline pemphigus foliaceus (abstract) [abstract]. Vet Dermatol. 2011;22:298.

94. Graham-Mize CA, Rosser EJ. Bioavailability and activity of prednisone and prednisolone in the feline patient. Vet Dermatol. 2004;15:7-10.

95. Center SA, Randolph JF, Warner KL, Simpson KW, Rishniw M. Influence of body condition on plasma prednisolone and prednisone concentrations in clinically healthy cats after single oral dose administration. Res Vet Sci. 2013; 95(1):225-30.

96. Rankin AJ, Sebbag L, Bello NM, Crumley WR, Allbaugh RA. Effects of oral administration of anti-inflammatory medications on inhibition of paracentesis-induced blood-aqueous barrier breakdown in clinically normal cats. Am J Vet Res. 2013;74(2):262-7.

Ready to submit your research? Choose BMC and benefit from:

- fast, convenient online submission

- thorough peer review by experienced researchers in your field

- rapid publication on acceptance

- support for research data, including large and complex data types

- gold Open Access which fosters wider collaboration and increased citations

- maximum visibility for your research: over $100 \mathrm{M}$ website views per year

At BMC, research is always in progress.

Learn more biomedcentral.com/submissions 